PALAVRAS. Revista de Epistemología, Metodología y Ética del Psicoanálisis

ISSN: 2468-9831

www.revistas.unlp.edu.ar/palavras

palavras@outlook.com.ar

Argentina

\title{
EL CASO DE SILVIA BLEICHMAR: UNA RECEPCIÓN ARGENTINA DEL PSICOANÁLISIS FRANCÉS CONTEMPORÁNEO
}

\author{
[THE CASE OF SILVIA BLEICHMAR: AN ARGENTINE RECEPTION OF \\ CONTEMPORARY FRENCH PSYCHOANALYSIS]
}

DOI $10.24215 / 24689831 \mathrm{e} 027$

Ariel Viguera

\begin{abstract}
The main objective of this article is to systematize -from the perspective of a reception study- the emergence of a current postlacanian current of Argentine psychoanalysis, sustained in the construction of a theoretical-clinical model that unfolds in the work of psychoanalyst Silvia Bleichmar (1944-2007). Bleichmar's is an exemplary case of a group of intellectuals who accessed French psychoanalysis in Argentina by an alternative route to that established by Oscar Masotta: the so-called "Althusser path", inspired by the reading that the philosopher will make of the work of several referents of French thought in the 70's. On the other hand, it is a theoretical-clinical model that studies and at the same time distinguishes both the production of subjectivity and the constitution, organization and functioning of psychism, which then allows the investigation of the points of contact between both dimensions. This ability to cross these dimensions renews the power of psychoanalysis by safeguarding its fertility and explanatory scope over time, insofar as it provides the necessary tools to review in each era the ideological pregnancies that can parasitize the conceptual network when folded to premises derived from the production of subjectivity of each historicalsocial time.
\end{abstract}

Key-words: Psychoanalysis - Postlacanism Bleichmar - Subjectivity
Resumen

El objetivo principal de este artículo es sistematizar desde la perspectiva de un estudio de recepción- el surgimiento de una corriente actual poslacaniana del psicoanálisis argentino, sostenida en la construcción de un modelo teórico-clínico que se despliega en la obra de la psicoanalista Silvia Bleichmar (1944-2007). El de Bleichmar constituye un caso ejemplar de un conjunto de intelectuales que accedieron al psicoanálisis francés en Argentina por una vía alternativa a la establecida por Oscar Masotta: la denominada "vía Althusser", inspirada en la lectura que dicho filósofo realizara de la obra de varios referentes del pensamiento francés en la década del 70'. Por otra parte, se trata de un modelo teórico-clínico que estudia y a la vez distingue tanto la producción de subjetividad como la constitución, organización y funcionamiento del psiquismo, lo cual permite luego la investigación de los puntos de contacto entre ambas dimensiones. Esta capacidad de cruzar dichas dimensiones puede renovar la potencia del psicoanálisis salvaguardando su fecundidad y alcance explicativo a lo largo del tiempo, en la medida en que provee de las herramientas necesarias para revisar en cada época las pregnancias ideológicas que puedan parasitar la red conceptual al plegarse a premisas derivadas de la producción de subjetividad de cada tiempo histórico-social.

Palabras clave: Psicoanálisis - Poslacanismo Bleichmar - Subjetividad

\section{Cómo citar este artículo:}

Viguera, A. (2019). El caso de Silvia Bleichmar: una recepción argentina del psicoanálisis francés contemporáneo. Palavras. Revista de Epistemología, Metodología y Ética del Psicoanálisis, 5, 1-37. Recuperado de www.revistas.unlp.edu.ar/palavras 


\section{EL CASO DE SILVIA BLEICHMAR: UNA RECEPCIÓN ARGENTINA DEL PSICOANÁLISIS FRANCÉS CONTEMPORÁNEO}

\section{Ariel Viguera *}

\section{Introducción}

El objetivo principal de este artículo es sistematizar -desde la perspectiva de un estudio de recepción- el surgimiento de una corriente actual poslacaniana del psicoanálisis argentino, sostenida en la construcción de un modelo teórico-clínico que se despliega en la obra de la psicoanalista Silvia Bleichmar desde 1981 hasta 2007. Puede identificarse la corriente mencionada como una variante forjada a partir de un psicoanálisis francés contemporáneo alternativo a la corriente inaugurada por Jacques Lacan. Cabe señalar que el estado de investigación sobre el tema es limitado, debido a que la mayoría de los estudios sobre el psicoanálisis francés se han centrado en el análisis de la recepción de la obra de Lacan y el lacanismo, que como se sabe representa en la actualidad la corriente hegemónica y mayoritaria del psicoanálisis argentino.

Sin embargo, el caso de Silvia Bleichmar constituye una referencia clave como caso ejemplar de un conjunto de intelectuales que accedieron al psicoanálisis francés en nuestro país por una vía alternativa a la establecida por Oscar Masotta: la denominada "vía Althusser", inspirada en la lectura que dicho filósofo realizara de la obra de varios referentes del pensamiento francés en la década del 70' (Carpintero y Vainer, 2004; Dagfal 2009). Dicha autora realizó una particular recepción de los desarrollos del psicoanalista Jean Laplanche, quien formó parte de un movimiento intelectual identificado como poslacanismo -siguiendo una expresión establecida en 1990 por André Green- constituido por un grupo de las primeras generaciones de discípulos de Lacan que, a partir de la década del 60', tomarian

\footnotetext{
* Facultad de Psicología de la Universidad Nacional de La Plata, Argentina. Mail: arielviguera@gmail.com
} 
distancia de su maestro para configurar, sin proponérselo, un movimiento convergente del psicoanálisis francés contemporáneo con características comunes (Urribarri, 2009). La recepción argentina de dicho movimiento se sintetiza con claridad a través de la expresión "ni sin Lacan ni sólo Lacan", (Hornstein, 1995), popularizada particularmente por la Revista Zona Erógena, surgida de un colectivo de estudiantes de Psicología de la Universidad de Buenos Aires que se convertiría en la publicación insignia del poslacanismo argentino durante toda la década del 90'. La posición asumida por los actores de dicho movimiento no implicó un rechazo explícito a las ideas y aportes teóricos de Lacan -que muy por el contrario sus ex discípulos siempre valoraron en profundidad- pero sí una discrepancia fuerte respecto de aspectos que consideraron: intelectualmente dogmáticos; institucionalmente autoritarios y/o clínicamente iatrogénicos.

Silvia Bleichmar nació en Bahía Blanca en 1944 y murió en Buenos Aires en 2007. Obtuvo los títulos de Socióloga y Psicóloga en la UBA en 1971 y 1972 respectivamente. Dejó una obra que todavía se está publicando, en función de la cantidad de materiales en elaboración que van siendo editados y compilados por quien fuera su pareja, Carlos Schenquerman y por su hija, Marina Calvo, ambos psicoanalistas. Puede sistematizarse su producción en dos grandes categorias de textos: por un lado, los que denominamos metapsicológicos, en los cuales encontramos producción y desarrollo de tesis y conceptos psicoanalíticos vinculados fundamentalmente a lo que constituye su modelo teórico-clínico. Por otra parte, otro conjunto de textos que son más bien ensayos, es decir, textos donde la autora reflexiona criticamente sobre la sociedad argentina, desde los fenómenos vinculados a las instituciones educativas, pasando por la formación de psicólogos y psicoanalistas hasta las crisis coyunturales y unos cuantos tópicos más. En definitiva una cantidad de ensayos y artículos publicados en diarios y revistas culturales donde Bleichmar aparece desempeñando un rol caracterizado como "intelectual de la esfera pública" (Vezzetti, 1994). Hugo Vezzetti advirtió rápidamente la insalubre combinatoria entre los efectos de la dictadura cívico-militar y 
los años 90' en Argentina, y señaló ya en ese momento que el psicoanálisis estaba perdiendo el relieve heroico y la vocación crítica; y que solo estaba impactando en la cultura bajo el peso creciente de la cultura de los medios. Para el pionero de los historiadores del campo psi argentino, los psicoanalistas en dicho país se venían distanciando cada vez más respecto de la tradición del intelectual que se afirmaba, ante todo, por la definición autónoma de los problemas, quedando poco a poco integrados al efecto global de un medio que operaba por saturación de temas. Si tomamos la diferencia establecida por Vezzetti, al momento de la crisis del 2001 en Argentina los psicoanalistas que se manifestaron públicamente desde un ejercicio intelectual de reflexión deliberante podian contarse con los dedos de una mano. Silvia Bleichmar era una de ellos (Plotkin y Visacovsky, 2007).

El modelo teórico-clínico forjado a lo largo de su trayectoria por Bleichmar no sólo se ha implantado en la formación de profesionales del campo psi en el grado y posgrado universitario argentino sino que puede afirmarse que ha introducido transformaciones importantes en los modos de ejercicio de la clínica de niños y adolescentes, con efectos de irradiación hacia territorios extranjeros como Francia, México y Brasil. En efecto, varios de sus libros han sido traducidos y publicados en dichos países recibiendo críticas elogiosas y deviniendo objeto de recepción. Al interior de su país, también dio clases en posgrados universitarios en las provincias de Córdoba y Rosario, así como en la ciudad de La Plata en la UNLP. En 2013 se produjo la creación, en la Facultad de Psicología de Rosario, de la "Cátedra Libre Silvia Bleichmar”. En México obtuvo reconocimiento en el período 1976-1986, ya que vivió allí durante los años de la dictadura cívico-militar que la obligaron al exilio, destacándose particularmente por su trabajo en la catástrofe ocasionada por el terremoto que azotó al país centroamericano en 1985: Bleichmar junto a Schenquerman coordinaron actividades de UNICEF de ayuda a las victimas (Bleichmar, 2010). En los años previos además fue cabeza editorial de la Revista Trabajo del Psicoanálisis, una publicación emblema de la difusión de la corriente que caracterizamos anteriormente y que prestaria su 
propuesta programática para el surgimiento posterior en Argentina de la revista Zona Erógena.

Si bien el mayor reconocimiento público está ligado a la clínica con niños, cabe aclarar que su propuesta es en rigor un modelo válido para el ejercicio de una clínica psicoanalítica en general, no exclusivamente centrada en un determinado tipo de pacientes o edades. Desde 1996 hasta 2007, año de su fallecimiento, dictó de manera anual y sistemática seminarios abiertos, los primeros años en el Hospital de Niños Ricardo Gutiérrez de la Ciudad Autónoma de Buenos Aires, y posteriormente en la Sociedad Armenia, con una asistencia promedio de 200 alumnos cada año. Las publicaciones que aún se hallan en edición y prensa se corresponden con las desgrabaciones de las clases dictadas en ese ámbito, publicadas hasta ahora por las editoriales Amorrortu y Paidós (Bleichmar, 2000; 2009a; 2011; 2014 y 2016).

\section{Consideraciones metodológicas}

Se trata de un trabajo de investigación eminentemente teórico, que no obstante involucra aspectos de carácter tanto teórico-clínico como teórico-aplicado. Por un lado trabajamos a partir de la exégesis de textos sobre fuentes primarias y desarrollos actuales sobre el tema estableciendo operadores de lectura para organizar el análisis de las obras de los referentes principales seleccionados, y sistematizar una periodización y una perspectiva panorámica de conjunto. Por otra parte, para el tratamiento del marco teórico desde una perspectiva histórica nos servimos del concepto de recepción, que consideramos fecundo atendiendo a que nuestro estudio se refiere a la implantación local de una corriente teórica foránea. Extraída de la teoría de la comunicación literaria de Hans Robert Jauss, esta noción se sitúa en el marco de la tradición hermenéutica alemana (Jauss, 1978, 1981; Varela 2002). Según Jauss, si la literatura, más allá de la simple representación, es por un lado capaz de crear nuevas realidades (produciendo sus condiciones de posibilidad, formando la sensibilidad estética del público y renovando su percepción), por otra parte el lector ejerce sobre ella una 
función de selección, determinada por su punto de vista particular, por su propia perspectiva. Para Jauss, la actitud del lector frente a una obra es modelada por todo un sistema de referencias objetivamente formulable. Apoyándose en la categoria husserliana de "horizonte de lo vivido", Jauss llama a este sistema de referencias "horizonte de expectativas", al que considera como el fruto de una experiencia intersubjetiva. Reconocidos historiadores del "campo psi" argentino han señalado cómo esta concepción compleja de los procesos de recepción debería permitirnos entender la excepcionalidad constitutiva de dicho campo, explicada desde la recepción del pensamiento francés y la excepción cultural francesa (Vezzetti 1998; Dagfal 2004 y 2009).

\section{Una periodización posible}

Siguiendo una lectura exhaustiva de la obra de Silvia Bleichmar podemos establecer tres períodos para sistematizarla complementando la bipartición mencionada previamente respecto a los textos metapsicológicos y de corte ensayístico.

Un primer período que delimitamos entre los años 1977 y 1990, en el cual toda su producción es claramente metapsicológica, propia de alguien que está en formación: todos los escritos de esta época giran en torno a la redacción de la tesis doctoral que realizara bajo la dirección de Jean Laplanche durante el exilio, entre México y París. Como veremos más adelante, la hipótesis principal de la tesis -la de plantear el concepto freudiano de represión originaria como real y cercable en la clinica con niños- va a constituir el fundamento de partida para toda una elaboración posterior que desarrollará las consecuencias teóricas y clínicas que se desprenden de tal postulación. En ese período se publica su primer libro: En los orígenes del sujeto psíquico. Del mito a la historia (Bleichmar, 1986), fruto de la tesis doctoral; pero consideramos parte de esa primera etapa también la publicación de un artículo programático clave en una compilación de varios autores aparecida en 1990. Dicho artículo es Lo inconsciente: fecundidad clinica de sus paradigmas y formó parte del libro Lecturas de Freud (Bleichmar, 1990). Lo incluimos 
como cierre del primer período porque se trata de un texto de enorme densidad conceptual, caracterizado por una lectura minuciosa del texto de Freud de 1915, en el cual Bleichmar establece una posición y ofrece al lector las coordenadas epistemológicas centrales de su lectura de la fuente primaria origen del psicoanálisis, complementando en profundidad las explicaciones metapsicológicas expuestas en su primer libro.

El segundo período lo situamos exactamente en la década siguiente, desde 1991 a 2000, pero el criterio para delimitarlo de ninguna manera responde a un agrupamiento por décadas sino a las características de su producción, lo cual da como resultado casual la coincidencia con la década mencionada. Este período se caracteriza por la sistematización y organización de lo que constituye el modelo teórico-clínico sobre algunos textos eje, y tiene en el centro a su segundo libro La Fundación del inconsciente (Bleichmar, 1993), quizá el de mayor densidad metapsicológica, seguido de un capítulo publicado en una compilación vinculada a un coloquio sobre Temporalidad, determinación y azar (Bleichmar, 1994) y coronado por la publicación en el año 2000 de las desgrabaciones revisadas de su primer seminario dictado en el Hospital Gutiérrez en 1996: Clinica psicoanalitica y neogénesis (Bleichmar, 2000).

Finalmente, un tercer período desde el 2001 hasta su muerte, donde se consolida como una de las referencias principales de una corriente actual psicoanalítica argentina y a la vez como intelectual de la esfera pública. Aquí aparecen sus publicaciones en diarios y revistas que luego son compiladas en los libros de ensayo, el primero de los cuales se llamó Dolor País (Bleichmar, 2002) editado al mismo tiempo en Buenos Aires y en París; seguido por No me hubiera gustado morir en los '90, unos años después (Bleichmar, 2006a). Pertenecen a esta época también Violencia social / violencia escolar, que reflexiona críticamente sobre el sistema educativo argentino (Bleichmar, 2008); y Superar la inmediatez: Un modo de pensar nuestro tiempo-, que compila entrevistas en diversos medios e intervenciones en programas de radio (Bleichmar, 2009b). Por otra parte, por la linea metapsicológica este período 
también se diferencia del anterior, ya que se caracteriza por la aplicación del modelo a zonas específicas de interés en las que desarrolla nuevas ideas. Una de las temáticas abordadas es la subjetividad, la cual da lugar a los libros La subjetividad en riesgo, (Bleichmar, 2005); y El desmantelamiento de la subjetividad y el estallido del Yo pocos años después (Bleichmar, 2009c) seguido de La construcción del sujeto ético (Bleichmar, 2011), y Vergüenza, culpa y pudor, (Bleichmar, 2016) que coronan una propuesta de reflexión sobre el estatuto del discurso psicoanalítico y su incidencia en la cultura. El otro tópico característico de sus investigaciones en este último período lo sintetizan Paradojas de la sexualidad masculina (Bleichmar, 2006b), que contiene también uno de los desarrollos y aportes más originales de su pensamiento, y Las teorías sexuales en psicoanálisis (Bleichmar, 2014). Entonces, en la categoría que llamamos metapsicológica se manifiesta un interés por la refundación conceptual de temáticas íntimamente ligadas (y necesarias) al eje de su participación como intelectual reflexiva al servicio de la sociedad y de los ensayos que iba publicando en los medios. Por último, La construcción del sujeto ético y Vergüenza, culpa y pudor reflejan su vocación de poner énfasis en la reconstrucción del tejido social y los lazos con el semejante (Bleichmar, 2011 y 2016).

\section{Primer periodo: en los origenes del modelo}

En los inicios de su práctica, Bleichmar comenzó a trabajar con niños justo en el momento en que empezaba a producirse en la Argentina la caída de un modelo del psicoanálisis cuya práctica se caracterizaba por el establishment, el sentido común, la creencia en el analista como autoridad y en su posición de saber, no solo como garantía respecto del conocimiento del inconsciente, sino como garantía ideológica con respecto a la vida (Vezzetti, 1983; Schenquerman, 2001). Tal es así que la vivencia de muchos psicoanalistas argentinos a fines de los 60' era la de que se producía algo del orden de una revolución epistemológica, con el cuestionamiento a la hegemonía de las asociaciones psicoanaliticas, y 
la entrada fuerte del pensamiento de Lacan, tanto por la vía Masotta como por la vía Althusser, (Klappenbach, 2000; Calabresi \& Polanco, 2011; Viguera, 2013 y Starcenbaum, 2014). Momento histórico en el que por primera vez se plantea en el psicoanálisis argentino un debate con el innatismo, específicamente con la idea de dejar de pensar el inconsciente como existente desde los orígenes de la vida. En efecto, si el inconsciente no era algo con lo que se nace, si el inconsciente no era el efecto de la inscripción de lo biológico en lo psíquico, se abría allí un interrogante problematizador en la medida en que la pregunta que venía a continuación era qué hacer con el análisis de niños, porque ya no estaba claro cuáles eran las premisas que podian regir la analizabilidad. Las preguntas de partida de Bleichmar en los 70' por lo tanto fueron: ¿qué es lo que permite instalar una práctica psicoanalitica con niños y cuáles son los prerrequisitos que la posibilitan? ¿Cómo se define? ¿A partir de qué se define? ¿Cuál es el momento de la instrumentación de una cura analítica con niños? Partiendo de que el análisis se regía por ciertos principios que habia que determinar si eran posibles de ser aplicados, en caso de que no lo fueran la autora problematizaba de qué manera habia que crear las condiciones o bajo qué premisas se podia producir una transformación del sufrimiento existente en algo de otro orden. Primera cuestión entonces, a la cual solia referirse en términos de "aperturas e impasses del estructuralismo y del innatismo". Lo que trataba de señalar era que el ingreso del lacanismo traía muchas más preguntas enigmáticas que respuestas acabadas, obligando a un verdadero trabajo de reordenamiento epistémico para definir dicho campo. Revisando los aportes de Jacques Lacan la autora no ocultaba la fascinación que le había producido descubrir en los años 70' que el inconsciente podía ser pensado como efecto de la acción sexual del otro, es decir como un elemento residual producido en la relación sexualizante con el semejante. Sin embargo marcaba también que uno de los problemas que arrastró el estructuralismo en los momentos en que se produjo este descubrimiento fue una gran relativización de los tiempos históricos, convirtiéndose el proceso de fundación del inconsciente en un momento mítico y no en un momento que los 
psicoanalistas pudieran rastrear en los tiempos de la constitución psíquica. Así se propuso lo que entendió como "el rescate del inconsciente": si -de acuerdo en parte con la enseñanza lacaniana- no lo concebía como existente desde los orígenes, se le imponía la necesidad de arbitrar los medios para determinar -en cada consulta infantil- si el inconsciente estaba o no operando, es decir si se había establecido o no lo que más adelante llamaría su fundación. Dicho de otro modo: le era necesario definir los parámetros a partir de los cuales se separaba del innatismo por un lado y del estructuralismo que consideraba ahistoricista por el otro, para establecer con claridad en qué momento era viable empezar un análisis infantil en sentido estricto. Fue esa problematización particular la que constituyó la rampa de lanzamiento por la cual Bleichmar resignificó las lecturas que había realizado de los textos de Jean Laplanche con los que había tomado contacto en la previa del exilio. Y el concepto clave para resolver la encrucijada fue precisamente el de represión originaria ya que a partir de su operatoria lograda, fallida o incluso ausente podría determinarse el diagnóstico y la dirección del tratamiento así como los modos de intervención del analista. En síntesis, la redefinición de la práctica analitica con niños exigía para Bleichmar la fundamentación de una Metapsicología del Aparato Psíquico, pensado éste como un aparato psíquico en constitución.

Silvia Bleichmar ha relatado en diversos textos y entrevistas su encuentro con la obra de Laplanche y con Jean Laplanche en persona después. La impugnación del kleinismo estaba ya avanzada en Argentina, y la impronta del pensamiento epistemológico francés se filtraba por la recepción de autores como Bachelard, Canguilhem, Foucault y Althusser. Recordemos que esta es también la época en la que Raúl Sciarretta daba sus grupos de estudio en los que se trabajaban estos autores (Viguera, 2013). Con la llegada de la dictadura y el exilio obligado a México, Bleichmar se vinculó con otros exiliados de diversas disciplinas humanas y uno de ellos la advirtió acerca de la posibilidad de realizar estudios de posgrado en la Universidad de París a través de la embajada francesa, lo cual la puso en contacto directo con 
Laplanche. Bleichmar historizó posteriormente aquel encuentro con la siguiente reflexión:

Hay una elección, no llego azarosamente a él. Llego pensando en una línea que tiene que ver con un rescate del freudismo desde una postura que está atravesada por el pensamiento epistemológico francés de los años 60'. Luego lo voy conociendo muy bien y me entero que fue compañero en la Ecole Normal de Foucault, de Althusser, es decir que tuvo una formación dentro de todo ese movimiento. Inclusive fue fundador de Socialismo y Barbarie junto con Castoriadis, formaron parte de todo ese grupo de intelectuales. Hay un pensamiento que yo siento que es muy riguroso en él, un pensamiento muy sólido, y cuando lo veo por primera vez y conozco las problemáticas que relataba antes y que no conocía vuelvo en el avión leyendo El Inconsciente y el Ello y me impacta mucho porque ahí veo las polémicas que están en juego y el debate con el estructuralismo. (Bleichmar, 2009b, 164).

El proyecto de tesis de Bleichmar atrajo intelectualmente a un Laplanche en plena batalla de ideas con un lacanismo que, a su juicio, poco después de haber introducido una subversión fecunda en el freudismo se encaminaba en algo del orden del extravío respecto de la exigencia freudiana. Laplanche pensaba que la impronta estructuralista en el psicoanálisis francés producía un efecto iatrogénico que consistía en envolver de un manto de supuesta falsedad todo lo que era del orden de lo histórico-acontencial en los sujetos, a partir de un uso particular de la categoría de lo imaginario que peyorizaba y convertía en irrelevante la pregunta por cómo se construye la estructura psíquica. Además, en el campo del psicoanálisis de niños, todo el acento recaía sobre la configuración psíquica de los padres y singularmente de la madre en tanto el sufrimiento infantil era considerado síntoma emergente de la pareja parental. En ese marco, la propuesta de Bleichmar de rastrear en la clínica misma el carácter real y no mítico de la represión originaria -y en el concepto de metábola establecido por el francés- para avanzar en una metapsicología fundacional del aparato psíquico, entusiasmó y gratificó a Laplanche. En efecto, alguien quería ocuparse de verificar casi popperianamente en la clínica con niños -una clínica a la que Laplanche nunca se dedicó- sus premisas teóricas, para 
reforzar y visibilizar entre otras la idea de que entre la estructura de partida, preexistente en los adultos, y la de llegada, el psiquismo del niño, se intercalaba un proceso complejo de metábola que cuestionaría radicalmente la homotecia entre las estructuras postulada desde el estructuralismo. Así se forjaron las bases de un intercambio fecundo entre México y París, motorizado por la pulsión epistemofílica de una exiliada argentina que rápidamente encabezaria la construcción de un colectivo instituyente de influencias y operaciones de recepción entre los tres países.

\section{Las Revistas Trabajo del Psicoanálisis y Zona Erógena: de México a Buenos Aires}

A poco de inscripta la tesis de Bleichmar en territorio universitario francés, hecho que se sustanció en 1979, los viajes ya no serían unidireccionales: el mismo Laplanche comenzaria a viajar a México para dictar conferencias a un grupo de exiliados argentinos y psicoanalistas mexicanos que iban a nuclearse en torno a la creación de la Revista Trabajo del Psicoanálisis, fundada por Bleichmar en 1981 junto a su pareja, Carlos Schenquerman. La primera editorial estaba a cargo de Laplanche, quien afirmaba:

\footnotetext{
Una nueva revista de psicoanálisis ve el dia, en un tiempo y un lugar que no son indiferentes. El lugar es México, lugar de acogida, encrucijada de ideas, punto de equilibrio y punto cálido, que permite una reflexión a la vez viviente y calma, entusiasta y serena entre el Sur, el Norte y la lejana y próxima Europa (Laplanche, 1981: 7).
}

El primer trabajo de la revista era la desgrabación revisada de la conferencia programática con la que Laplanche había presidido su inauguración, el 25 de febrero de 1981 en el Instituto Francés de América Latina, la cual llevaba por título El estructuralismo ¿sí o no? Allí, el autor afirmaba que la hipótesis del inconsciente estructurado como un lenguaje constituía "una hipoteca que debía ser levantada", en tanto dejaba por fuera -retomando su texto de Bonneval (Ey, 1970)- ni más ni menos que el nivel de simbolización más profundo del inconsciente, aquel que consideraba del orden de la pulsión de muerte, 
y que proponía imaginar compuesto de elementos discretos, fragmentados, que no significaban más que a sí mismos (Laplanche, 1981). Alentaba al auditorio a teorizar un tipo particular de simbolización más allá de lo simbólico lacaniano, para estudiar las vicisitudes de un proceso creador que desafiaba toda reducción formalista a un orden lógico preestablecido.

A partir de ese momento, Trabajo del Psicoanálisis publicaría 12 números, en el período 1981-1991, los ocho primeros en México y los últimos ya en Argentina, acompañando el regreso de los exiliados a dicho país, en 1986. Cada uno de los doce números tuvo en su interior un artículo de Jean Laplanche, y con frecuencia participaron Pierre Fedida, Guy Rosolato y Maurice Dayan entre otros franceses. Por supuesto Bleichmar fue publicando alli las versiones previas de los capitulos de la tesis que iba elaborando hasta defenderla en 1983, y poco a poco se incorporaron otros psicoanalistas argentinos $\mathrm{y}$ mexicanos, como Carlos Schenquerman; Rafael Paz; David Rosenfeld; Hugo Bleichmar; Hugo McCormick; Horacio Etchegoyen; David Maldavsky; Fernando González; Luis Hornstein; Vicente Galli; Emiliano Galende; Gillou García Reynoso; Bruno Winograd; Ricardo Avenburg; Marcos Bernard y Janine Puget. La revista cerró su edición con un número doble que incluyó la publicación de las actas de un evento organizado por este colectivo que ya llevaba 5 años reinstalado en nuestro país con el retorno de la democracia. Se trató de las Jornadas Encuentro con Jean Laplanche: El inconsciente y la clinica psicoanalitica, trabajar sus fundamentos, realizadas en el Colegio Nacional de la Universidad de Buenos Aires del 6 al 10 de noviembre de 1990, con la participación de Jean Laplanche junto a psicoanalistas llegados desde Brasil, Uruguay, Paraguay y de algunas ciudades del interior del país como Rosario, Córdoba, Neuquén y Misiones. El evento fue coorganizado también por la incipiente Revista Zona Erógena, a cargo de un grupo de estudiantes de la carrera de Psicología de la UBA, dirigida por Fernando Urribarri, quien tuvo un lugar como expositor en el panel de cierre. En su exposición, Urribarri explicitaba la decisión conjunta de las comisiones editoriales de ambas revistas para que Zona Erógena, 
que llevaba 4 números en la calle desde su aparición en 1989, tomara la posta dejada por Trabajo del Psicoanálisis. Se presentaba como representante de una nueva generación que hacía su ingreso al psicoanálisis argentino tomando a su cargo el compromiso de situarse en relación a los referentes mayores en una posición significativa que les permitiera hacer trabajar sus propuestas y trascenderlas. Admitía el valor programático que la obra de Laplanche y Bleichmar habian tenido en la fundación de la nueva revista y enfatizaba en la idea de un punto de relanzamiento (Urribarri, 1991).

El primer número de Zona Erógena había comenzado un año atrás con un reportaje exclusivo a Laplanche seguido de un texto inédito de Bleichmar, y para el momento de realización del evento al que hacemos referencia ya alcanzaba una tirada de 5.000 ejemplares, y había incorporado secciones ligadas a otras disciplinas sociales como la sociología, la filosofia y la literatura, siempre con el perfil de los estudiantes de la UBA. La publicación terminaría cumpliendo con creces el objetivo enunciado por Urribarri en aquella ponencia, editando ininterrumpidamente cerca de 50 números hasta su cierre una década después, en el año 2001, afectada entre otras cosas por la tremenda crisis político-económica que atravesó nuestro país en ese año. La tirada de ejemplares fue creciendo de manera exponencial a cada año que pasaba, y la revista llegó a convertirse en la publicación insignia que nucleó a la vertiente argentina de lo que denominamos previamente psicoanálisis francés contemporáneo o poslacanismo argentino.

Volviendo al recorrido de Silvia Bleichmar, subrayamos el papel preponderante que desempeñó como referente del poslacanismo argentino, no sólo a través de la fundación de su revista y la colaboración con Zona Erógena, sino también porque durante sus estudios de doctorado en el exilio se encargó de traducir los seminarios que Laplanche dictaba en la Universidad de París. Las ideas y los libros de Laplanche retornaron como lo reprimido gracias a la gestión académica de Bleichmar, ya que durante la dictadura el lacanismo argentino ya había advertido y conocido las vicisitudes institucionales y los quiebres entre Lacan y su primera linea de discipulos, desalentando 
el uso del conocido Diccionario de Psicoanálisis publicado en coautoría con Pontalis. Una de las vías de difusión de las diferencias surgidas en el coloquio de Bonneval de 1960 la constituyó la tesis doctoral -sobre Lacan- de una joven belga, Anika Rifflet-Lemaire. La tesista examinó en detalle aquella polémica, y Lacan, advertido de ello, le escribió el prólogo y se pronunció al respecto. Ese libro fue una de las fuentes secundarias más consultadas durante la implantación del lacanismo en nuestro país hasta fines de los años 80' (Rifflet-Lemaire, 1971). El retorno de la obra reprimida cobró mayor fuerza cuando se publicó en Argentina la tesis doctoral hecha libro de Bleichmar, y a ello se sumó el éxito editorial de Zona Erógena y las visitas frecuentes al país no solo de Laplanche, sino también de Green, Castoriadis y Conrad Stein entre otros, en eventos organizados por la misma revista.

\section{En los origenes del modelo: ¿quién sufre y por qué?}

En varios capítulos de su tesis doctoral ya devenida libro, la autora explicitaba su deuda intelectual con Laplanche sobre todo como inspirador de una metodología de trabajo sobre la obra freudiana y por lo tanto de sus decisiones a medida que iba leyendo a Freud, lo cual la llevaba a tomar partido por el eje teórico de pensar el inconsciente como el producto de un complejo sistema de metabolizaciones simbólicas que se constituye en el interior de las relaciones sexualizantes y de prohibiciones que en esa época llevaban todavía el nombre de "estructura edípica". Por otra parte, señalaba que era en el marco de la tópica psíquica, definida por juegos de instancias en conflicto, donde el síntoma se producía y cobraba valor simbólico en tanto conflicto intrapsíquico, es decir inter-sistémico. Dichas premisas operaban como organizadoras tanto del diagnóstico como de los criterios de analizabilidad y direcciones posibles de un tratamiento psicoanalítico. Criterios que podian mantenerse vigentes pero que requerian ser complementados por una revisión que permitiera establecer modos de intervención para los analistas cuando las condiciones para un análisis en sentido estricto no estuvieran dadas. Modos de operar que pasarian 
a ser justamente el prerrequisito para fundar las condiciones de análisis, es decir para que el sujeto -en constitución- transite de formas pre-neuróticas a modalidades neuróticas en su funcionamiento. En definitiva, explorar las condiciones del psiquismo desde una orientación teorética (Laplanche, 1981) que -considerando al inconsciente como fundado y no como existente desde los orígenes- le permitiera cercar los indicios de su existencia a través de la operatoria de la represión originaria. Desde estas coordenadas, Bleichmar establecía la diferenciación entre lo que podemos denominar dos modalidades de emergencia de signos patológicos: las categorias conceptuales de trastorno y de sintoma. Recuperaba a la vez la definición freudiana del síntoma como formación del inconsciente, como producto transaccional cuyo origen implicaba en sí mismo la existencia del clivaje del aparato psíquico que lo fundaba en el momento de instauración de la represión originaria. Es decir que para que hubiera síntoma este debía no sólo expresar una inlograda satisfacción pulsional, sino que debía ser el sujeto mismo (un sujeto del yo), quien se rehusara a una parte clivada de sí mismo que se había tornado extraña y "pulsante". El síntoma revestía entonces un carácter intrasubjetivo, a diferencia del trastorno, que la autora definía como la emergencia en lo manifiesto de una perturbación en el marco de las relaciones primordiales con el semejante en los momentos previos a la instauración de una neurosis infantil.

La pregunta ordenadora diagnóstica de Bleichmar podía resumirse como le gustaba decir- en quién sufre y por qué. Afirmaba que no hay sufrimiento neurótico si no hay un sistema que pague el precio del sufrimiento porque otro sistema goza, en el juego complejo de las relaciones intersistémicas entre deseo y defensa, con cargas y contracargas. Eran en definitiva las modalidades históricas singulares de la constitución psíquica las que se abordaban en el diagnóstico, para a partir de ello definir las estrategias terapéuticas. En los origenes del sujeto psíquico se publicó en la editorial Amorrortu en 1986, al regreso de Bleichmar desde México, lugar que no abandonó de inmediato al reanudarse la democracia argentina, básicamente por el compromiso 
contraído con los pacientes que tenía en análisis en el país que la había alojado en el exilio. Nuestra periodización propone concluir esta primera etapa con este acontecimiento, pero no sin incluir un texto en particular que ha tenido poca difusión y que sin embargo a nuestro criterio complementa una serie de aspectos clave para el diseño del modelo establecido por la autora. Nos referimos a un capitulo de un libro del que fue compiladora y que se llamó Lecturas de Freud (Bleichmar, 1990). Alli, Bleichmar realizaba una lectura comentada casi a la letra -o al estilo del trabajo que solía hacerse en el dispositivo conocido como grupo de estudio- del texto "Lo inconsciente" de Freud. El capítulo explicitaba las coordenadas epistemológicas desde las que abordaba la obra freudiana para poder afirmar y solventar lo que había postulado en su tesis doctoral. Señalaremos algunos ejes medulares que lo atraviesan: en primer lugar, reafirmaba la tesis del realismo del inconsciente explicitada por Laplanche, como se observa en la siguiente cita:

$\mathrm{El}$ inconsciente no se reduce, ni mucho menos, a su conocimiento. El hecho de que sólo podamos conocerlo mediante una "traducción" implica, por un lado, que no es posible subsumir conocimiento y existente. Freud está cercando claramente un objeto al que considera real, que tiene tanto leyes de existencia como de conocimiento, que no son asimilables unas a las otras, y al mismo tiempo que debe ser "transpuesto", "traducido", tornado otro lenguaje, transcripto a otra lengua -veremos luego que es en realidad transcripto en lenguaje- para que su conocimiento se haga posible (Bleichmar, 1990, 18).

En segundo lugar, la autora subrayaba cómo en ese texto Freud se proponía definir bajo qué circunstancias y en qué términos podía hablarse del inconsciente en sentido estricto como un sistema, dándole un estatuto metapsicológico: tópico (dónde se emplaza); dinámico (en qué relación de conflicto entra); y económico (qué energía lo ocupa y de qué modo dicha energía circula). También se preguntaba cómo operaban las relaciones de pasaje de un sistema a otro y analizaba el ir y venir de Freud respecto de las hipótesis tópica y funcional respectivamente (otro tema que había sido recuperado por Laplanche en 
Bonneval para responder a la crítica de Politzer y advertir a Lacan). Lo resolvía de la siguiente manera:

Si la hipótesis tópica es indispensable para la conservación de la diferencia entre los sistemas psíquicos y la vigencia de la represión, la hipótesis funcional pone el acento en este cambio de cualidad que sufre inevitablemente la representación al pasar de uno a otro sistema (Bleichmar, 1990, 19).

En definitiva, para la autora la hipótesis funcional y la tópica se complementaban, porque el pasaje de un sistema a otro implicaba también un cambio de cualidad, vale decir que si la representación-cosa no se ligaba a una representación-palabra no podía hacerse consciente, con lo cual ambas hipótesis no solamente eran válidas para lo reprimido, sino que además lo eran para el retorno de ese reprimido.

Así, al cierre de este primer período alcanzaba el objetivo de sistematizar la idea de una fundación de la represión originaria a partir de la instalación de contrainvestimientos de los representantes pulsionales que culminaban en las representaciones totalizantes del narcisismo, en el advenimiento del yo y en la división entre los dos grandes sistemas psíquicos.

\section{Segundo Periodo: tiempos y vicisitudes de la constitución psíquica}

La vía por la cual Bleichmar continuó la profundización del modelo fue precisamente la de delimitar con claridad lo que ya llamaba el paradigma de lo originario, es decir la elucidación de todos los tiempos previos y las condiciones para que la fundación del aparato fuera posible. Una vez resuelta la cuestión de cómo operaba la represión originaria y de dónde sacaba su fuerza, lo que seguía era responder la pregunta acerca de qué es lo que la represión originaria reprime y diferenciarlo de lo reprimido secundariamente. Si lo que se reprime es lo pulsional autoerótico implantado a través de la operatoria del otro humano en el interior de las relaciones sexualizantes, su preocupación consistiría entonces en abordar el modo de instalación del autoerotismo y de la circulación libidinal antes de que la represión originaria se 
produzca. Una de las expresiones que la autora acuñará para nominar esta temática será la de un "más acá del principio de placer".

Haciendo trabajar los postulados de Laplanche respecto de la fundación exógena de la pulsión y su teoría de la seducción originaria (Laplanche, 1987), la autora iba a definir el encuentro entre el cachorro humano y el adulto a cargo como radicalmente asimétrico, por cuanto el bebé cuenta sólo con montantes biológicos adaptativos y el adulto es un sujeto con inconsciente, que opera sobre la cría desde la intersección de dos sistemas presentes en los modos de ejercicio de la función materna, a la manera de lo que llamará un doble conmutador:

\begin{abstract}
Esta es la gran paradoja de la función materna, en el momento que satisface necesidades incluye excitaciones, introduce en ese movimiento, algo que no estaba previsto en el programa de la naturaleza, produciendo una profunda alteración de los modos automáticos de descarga y quebrando de entrada la inercia neuronal. A partir de ello ya no podrá haber descenso de la tensión a cero. Y cada vez que se pretenda evacuar esa cantidad, el aparato se recargará con tensiones de carácter interno, producto de sus sistemas de representaciones activadas por las zonas erógenas pulsadas en el acto de cuidado correspondiente. (...) La acción específica ha quedado totalmente subordinada a los modos de recomposición representacional excitante que ya no son atravesados sino por líneas de investimiento relacionadas con el deseo. (Bleichmar 2000, 301)
\end{abstract}

Entonces, desde el otro humano y a espaldas de su conciencia se agita en dicho encuentro la sexualidad infantil reprimida originariamente, transfiriendo e inscribiendo una excitación que desconoce (pulsación originaria la llamará la autora más adelante). Este proceso no es otro que el de la implantación misma de una fuente pulsional del lado de la cría, efraccionando su cuerpo biológico por líneas libidinales. Pero a la vez, desde su sistema preconcienteconciente regido por el narcisismo, aportará constelaciones representacionales organizadas al modo del proceso secundario, tanto preconscientes como reprimidas secundariamente. $\mathrm{El}$ otro adulto ejerce entonces su prioridad, parasitando sexual y representacionalmente a la cría, haciendo estallar los marcos de lo autoconservativo e inscribiendo 
sexualidad en sentido amplio, excitaciones inevacuables que van a devenir exigencias de trabajo psíquico y condición necesaria para la complejización del aparato psíquico. La sexualidad humana no nace entonces en continuidad con lo biológico sino en décalage de lo traumático de ese plus, de esa excitación imposible de evacuar. Desde su narcisismo los otros de crianza propiciarán también las ligazones de la excitación, posibilitando investimientos o vías colaterales, otra expresión conceptual freudiana poco utilizada y que para la autora deviene un concepto clave para tematizar los modos de inscripción de la materialidad psíquica en el aparato. En efecto, la conjunción de ese doble carácter de la función maternante, permite que la excitación de las zonas erógenas precipite en el cuerpo erógeno, constituyendo un primer tiempo de la sexualidad: el autoerotismo. Esta parasitación a la que hacemos referencia es la puerta de entrada al primer tiempo de la sexualidad, es el primer tiempo de la vida psíquica en el que se instala la pulsión:

Si no se inscribe la pulsión, no se producen los elementos básicos de la humanización, el aparato no es obligado a un trabajo psíquico: es la pulsión lo que lo obliga a someterse a un trabajo de dominio y ligazón impulsando a través de ello lo que llamamos crecimiento intelectual, crecimiento psíquico (Bleichmar 2000, 142).

En este período entonces Bleichmar ya estaba en condiciones de caracterizar los tiempos de constitución de lo originario del modo siguiente: a un primer tiempo de la vida caracterizado por montantes biológicos y atravesado por la necesidad le sucedía un primer tiempo de la sexualidad, en el que la pulsación originaria del otro subvierte este primer orden biológico dando origen a las primeras briznas de representación/simbolización, introduciendo algo del orden del exceso que exige y motoriza la complejización del psiquismo. Se trata de la implantación de la pulsión caracterizada por Laplanche, solidaria de la instalación del autoerotismo (Laplanche, 1996). Le seguía un segundo tiempo de la vida psíquica caracterizado por la operatoria de la represión originaria y la instauración de un yo-representación narcisista que reprime precisamente el autoerotismo previamente 
instalado constituyendo la matriz de las identificaciones primarias. El Yo consiste para la autora en una masa representacional vinculada a un conjunto de enunciados que van a posibilitar una primera estabilidad de un sujeto a partir de una legalidad y modos propios del proceso secundario. Diferencia el preconciente como modo de operatoria de la lógica, del Yo como lugar de investimientos narcisistas y sede del sujeto. A partir de estos desarrollos se abren otros muy fecundos acerca de las relaciones entre inteligencia y simbolización. El tejido representacional que constituye al Yo involucra la identidad de género, pero esta es una idea que aparecerá recién en el tercer período, una vez más a remolque de una conceptualización de Laplanche sobre la diferencia entre sexualidad y género.

Por último, continuaría un tercer tiempo de la vida psíquica, caracterizado por la fundación de las instancias ideales y la conciencia moral. Solidaria con este planteo aparecía una redefinición del concepto de infancia desde la perspectiva del modelo de la constitución subjetiva:

[...] la infancia es el tiempo de instauración de la sexualidad humana, y de la constitución de los grandes movimientos que organizan sus destinos en el interior de un aparato psíquico destinado al après-coup, abierto a nuevas resignificaciones y en vías de transformación hacia nuevos niveles de complejización posible. (Bleichmar 1993, 215).

Ya en las páginas finales de La fundación de lo Inconsciente, la autora sistematizaba una serie de conclusiones ordenadas en torno a un eje principal: la heterogeneidad de la materialidad psíquica, incluyendo al inconsciente como un sistema compuesto por elementos diversos, no homogéneos. Dicho eje se sostenía en la diferencia previamente establecida al responder la pregunta de qué reprimen, respectivamente, la represión originaria y la represión secundaria. En efecto, en el inconsciente "más originario" encontraban posicionamiento tópico todas aquellas representaciones efecto de metábola, nunca pasadas por el lenguaje ni capturadas por este en una significación, solo "cercables" por libre asociación aunque no restituibles. Siguiendo las premisas de la teoría de la seducción generalizada de Laplanche, Bleichmar insistía en aclarar que el sentido de las mismas tampoco podía ser buscado "en 
otro lado" (se refería a buscarlas del lado del psiquismo de la madre, como proponía el modelo de Maud Mannoni con el cual discutía desde los inicios de su práctica clinica) argumentando en clave laplancheana que se trataba de un sentido "para sí mismo ignorado". Por otra parte, también tenian estatuto inconciente otras representaciones, pero correlativas ya de la represión secundaria, y por lo tanto radicalmente distintas, ya que habian sido parte del preconsciente y en consecuencia habian recibido articulación significante al interior del código de la lengua. Es decir representaciones-palabra devenidas representacióncosa, originalmente surgidas de un proceso secundario pero circulando en un proceso primario luego de la represión. Además de ellas, la autora diferenciaba otro producto efecto de la misma causa (la represión secundaria), pero con otro rasgo distintivo: el de ser bloques enteros de fragmentos discursivos, reprimidos al modo de enclaves cristalizados, que no eran otros que los mandatos del Superyó, capaces de fijar al sujeto a determinadas constelaciones fantasmáticas.

Finalmente, en esa sistematización que establecía las bases de un modelo no sólo aplicable a la clínica de niños sino a la clínica en general y en especial a lo que la autora denominaba un psicoanálisis de frontera, había un lugar para un tipo de materialidad que denominará luego como signos de percepción:

Dejamos abierta la posibilidad de que ciertas inscripciones, efecto de traumatismos severos, no logren el estatuto de inconscientes y queden libradas a una circulación amenazante por la tópica psíquica cuya estabilidad ponen en riesgo. Estas representaciones, en su estatuto de manifiesto aun cuando no por ello de conciente, obligan a un tratamiento de ligazón más que de "des-represión" en el interior de la cura... Estas últimas dan lugar a trastornos, en razón de que por su imposibilidad de entrar en formaciones de compromiso, transaccionales, no permiten la formación de síntomas en sentido estricto (Bleichmar 2000, 205).

Este párrafo recuperaba de alguna manera lo que la autora había trabajado en los primeros capítulos de este libro clave del segundo período de su producción intelectual. Nos hemos ocupado en otros trabajos de analizar específicamente las referencias a los signos de percepción tanto en Bleichmar como en Laplanche para comparar los 
usos respectivos y avanzar con nuestras conclusiones respecto de la fecundidad del concepto y sus aplicaciones (Viguera, 2005; 2006; 2007).

Continuamos el análisis de los textos principales que agrupamos dentro de este segundo período de la obra de la autora, para ocuparnos de un capítulo que escribe para una compilación en torno al tema Temporalidad, Determinación y Azar, lo reversible y lo irreversible, en 1994. Se repite aquí un fenómeno que ya situamos en el período anterior: a un libro de neto corte metapsicológico le sucede un capítulo de una compilación que parece cumplir una función similar: la de sistematizar las coordenadas epistemológicas fundamentales que orientan la producción original de la autora en ese momento, operando como un complemento necesario y esclarecedor. El texto al que hacemos referencia es Repetición y temporalidad: una historia bifronte, un capítulo que no escapa al estilo clásico de la autora, en el sentido de que se compone de la enunciación de premisas claves del desarrollo teórico articuladas e ilustradas a partir de una viñeta clínica.

Tomando como eje una de las premisas convocantes del coloquio en el que le tocaba participar, Bleichmar comenzaba por sistematizar la presencia del par determinado-indeterminado en el interior de la obra freudiana, para extraer de allí consecuencias respecto de otro de los ejes de convocatoria: el de sistemas abiertos y cerrados en el marco del paradigma de la complejidad, que hacia mediados de los 90' se hallaba en pleno auge y expansión. La autora explicaba cómo era posible encontrar en la obra freudiana textos y momentos suficientes para solventar lecturas contrapuestas, enfatizando en la necesidad de una metodología de estudio de la obra que incluyera la toma de decisiones para trabajarla, como le enseñara Laplanche. Así, tomaba como ejes a la fundación del inconsciente; el origen de la pulsión y una teoría psicogenética de las neurosis, para afirmar:

El aparato psíquico es entonces un sistema abierto, capaz de sufrir transformaciones no sólo como efecto del análisis sino de las recomposiciones a las cuales nuevos procesos histórico-vivenciales lo obligan. Al mismo tiempo, y desde el punto de vista de la recepción, el inconsciente es también transformable: el hecho de que los elementos de 
base que lo componen sean indestructibles no quiere decir que sean inmodificables, en razón de que las relaciones que activan los diversos elementos en conglomerados representacionales -fantasías- nuevos son posibles (Bleichmar 1994, 52).

El párrafo que acabamos de leer es quizá una de las elaboraciones más fecundas de la autora, por la cantidad de consecuencias a nivel teórico-clínico que logró condensar en él. Posteriormente, articulaba la recepción que hacía de los desarrollos de Prigogine, para poner en diálogo a este aparato psíquico abierto con lo que aquel denominaba sistemas alejados del equilibrio, importando la noción de punto de bifurcación, definida como el punto exacto en que una solución primitiva se vuelve inestable y obliga a la producción de nuevas soluciones que pueden corresponderse con un comportamiento muy distinto de la materia. De este modo, el síntoma desde el psicoanálisis podia ser pensado como una recomposición espontánea a partir de la ruptura de un equilibrio anterior, y una relectura de la teoría del traumatismo devenía legitima y necesaria, articulada con la recuperación de lo histórico en psicoanálisis:

Desde esta perspectiva, el proceso de la cura puede ser concebido como espacio privilegiado de la resimbolización. Lugar de re-engendramiento a partir de que lo traumático no es lo vivido en general sino aquello que no pudo encontrar, en el momento de su inscripción y fijación, de su caída en el aparato, posibilidades metabólicas de simbolización productiva (Bleichmar 1994, 73).

Entonces la autora presentaba a la clinica psicoanalitica como un lugar de producción simbólica, solventando dicha afirmación en dos argumentos: en primer lugar porque en muchos casos se trataba de trabajar con un sujeto en constitución, y por otra parte porque pensaba que los distintos modos con los cuales opera la simbolización no se reducen a las formas clásicas que pueden encontrarse en el sujeto ya constituido. La consecuencia que se desprendia de estas formulaciones es que el análisis no se limitaba a reencontrar lo ya existente, sino a producir nuevos modos de simbolización que pueden haber estado ausentes en el momento en el que la consulta se realizaba. Por eso para 
ella la clínica psicoanalítica no implicaba solamente un lugar de recuperación de lo ya inscripto sino de producción de algo nuevo, para lo cual acuñó el concepto de neogénesis (Bleichmar, 2000).

La reelaboración de una teoría del traumatismo para pensar ni más ni menos que los orígenes de la simbolización y los modos de constitución del psiquismo por referencia a lo real y en particular a la incidencia del otro humano en dicho proceso no tardaron en aparecer en las preocupaciones de Bleichmar y tomaron forma sobre el cierre de este segundo período de su producción, a partir del seminario dictado en el año 2000. La autora recuperaba las conceptualizaciones de Laplanche para marcar el abandono freudiano de la teoría del trauma acontecido en 1897, leído -desde categorías epistemológicas kuhnianascomo la pérdida que se produce como consecuencia de una revolución intrateórica. A la vez, consideraba que la ganancia principal del giro revolucionario de la primavera de 1897 lo constituía la producción por Freud del concepto de realidad psíquica, aun cuando criticaba la circunstancia de que el mismo quedara subordinado en principio a una concepción endogenista del psiquismo solventada sobre la teoría que concibe a la pulsión como un efecto de delegación de lo somático en lo psíquico. Por supuesto desde las coordenadas de la tesis del realismo del inconciente establecidas por su maestro francés, la autora argentina iba a subrayar la virtud de que Freud definiera en aquel momento un espacio psíquico, que no se caracterizaba por estar afuera, tampoco se caracterizaba por ser subjetivo -entendido esto último como hallarse dentro de la posición del sujeto- sino que se definiría por su carácter de realidad en tanto materialidad psíquica que no está en contigüidad con la naturaleza. El concepto de realidad psíquica freudiana aludía para la autora a un sistema, a un conjunto de representaciones que son reales en la medida en que existen más allá del yo, del sujeto que enuncia, más allá de la realidad subjetiva, pero que al mismo tiempo son un orden de alteridad que no está por fuera del aparato psíquico. Fiel a la metodología de trabajo laplancheana sobre la obra originaria del psicoanálisis, Bleichmar buscaba las zonas del pensamiento de Freud que le permitían apuntalar sus afirmaciones. Por ejemplo, decía preferir 
el viejo concepto de huella mnémica -sepultado en la tumba de la neurótica en la que Freud ya no creía después de 1897- antes que el emergente de representante representativo de la pulsión. En la misma dirección, la encontraremos revisando el Proyecto de Psicología para Neurólogos para justificar la importancia del otro humano (el del auxilio ajeno) en la experiencia de satisfacción y su protagonismo fundamental a través de la paradoja de que en el acto de aliviar la tensión de la necesidad introduce algo que es siempre del orden de lo sexual en sentido amplio y que excede claramente a una cría humana en estado de prematuración. De este modo ponía al traumatismo de los primeros tiempos -entendido como eso que excede y desborda desequilibrando al psiquismo- en el lugar de causa originaria de la simbolización, en la medida en que obliga al aparato a un trabajo psíquico para intentar procesar las cantidades que lo excedieron. Por supuesto no refiere a lo sexual genital sino "a un plus de placer que no se reduce a la autoconservación”, y que se traduce en la inscripción de mínimas unidades representacionales que a su vez no reflejan en espejo el objeto del mundo del cual provienen. Bleichmar tomará como ejemplo la alucinación primitiva tematizada por Freud:

¿Qué característica tiene ese objeto? Ese objeto no es el pecho real del mundo, es decir, ese objeto no existe en el mundo, y al mismo tiempo ese objeto no es creado por el sujeto. Ese objeto es el efecto de una inscripción residual de un encuentro con un objeto del mundo, que podríamos decir del orden de lo real, y que se inscribe justamente por su exceso. Se inscribe porque no puede bajar la cantidad a cero, si solo se le diera leche al bebé y no calor y contacto y todo lo que le damos, esto no se produce... $\mathrm{El}$ traumatismo entonces, en este sentido, es productor de algo que implica un procesamiento que genera representación (Bleichmar 2008, 8).

\section{Tres paradojas en la tesis del realismo del inconsciente}

Hacia el final de este segundo período, para Bleichmar la constitución del inconsciente estaba atravesada en definitiva por las que consideraba tres paradojas. La primera la constituía el hecho de que en los origenes del psiquismo humano -que diferenciaba de los orígenes del 
inconsciente, en tanto este podía no constituirse- podía situarse específicamente la existencia de lo que denominaba un pensamiento sin sujeto, lo cual era paradojal en tanto contradice todo lo que podemos pensar del pensamiento: es impensable un pensamiento sin sujeto. Pero argumentaba que el concepto de representación tal como ha sido planteado desde los comienzos del psicoanálisis, alude al hecho de que hay un modo de pensamiento en el sentido más amplio, no un pensamiento pensado en términos filosóficos. Hay por lo tanto un tipo de representación en los orígenes del psiquismo que no es pensada por nadie, lo cual se convertía en algo extraordinario del descubrimiento psicoanalítico, muy poco puesto de relieve según Bleichmar porque atentaba contra un modo de ejercicio de la práctica psicoanalítica que se proponía someter a crítica: lo que denominó la resubjetivización del inconsciente. Se refería a la idea de que el inconsciente es algo del orden de un sujeto distinto del orden de la conciencia, lo cual se expresaba claramente en una práctica clínica en la cual se podía identificar el supuesto básico de que el analista y/o el paciente creen que lo que se tiene en el inconsciente es "otro" que piensa distinto al que piensa en la conciencia. Muy por el contrario, desde la tesis del realismo del inconciente este aparece tematizado como un espacio presubjetivo en los origenes, antes de que advenga un sujeto que piensa en sentido estricto, y parasubjetivo -es decir paralelo al sujeto- cuando este se ha constituido; en el cual hay representaciones que operan al margen de un sujeto que piense con la lógica del preconsciente. Le gustaba ejemplificar diciendo que los hombres podían pasarse la vida entera intentando esclarecer y domeñar esos "pensamientos que no fueron pensados por ellos", los de un "no entiendo como esto se me apareció en la cabeza", lo cual indica el carácter parasubjetivo de las representaciones inconscientes que pueden aparecer del lado de la conciencia o del preconsciente. En la lectura de Bleichmar entonces esta es la primer paradoja planteada por el freudismo: la reproducción de representaciones que no son pensadas por nadie, y que constituyen el realismo del inconsciente, vale decir su realidad y su no atravesamiento por la subjetividad, es decir por la duda o por la 
negación, teniendo por lo tanto un carácter de realidad existente, de res extensa.

La segunda paradoja que se desprende de la tesis del realismo del inconsciente radica en que el mismo se constituye a partir de representaciones que proviniendo del exterior han perdido sin embargo toda referencia al exterior. Nuestra autora ejemplifica esto utilizando el modelo freudiano de la primera vivencia de satisfacción suponiendo la cría humana como un organismo biológico en el momento en que se produce dicha vivencia. Bleichmar sostiene que la vivencia es algo que se produce sin que haya un sujeto que la capture, en el sentido de capturarla como experiencia, aunque algo quede inscripto. En ese momento se inscribiría una huella, incluso un conglomerado de huellas, un conjunto de elementos resultantes de esa vivencia que pueden ser nominados tomando la expresión conceptual freudiana signos de percepción. Lo que se inscribe son entonces un conjunto de signos de percepción, siguiendo el modelo de la carta 52, que no son ni inconscientes ni preconscientes en sentido estricto. Podría decirse que son representación en el sentido más amplio del término. Dichos elementos van a tener la característica de ser inevacuables, porque no se diluyen en la tensión de necesidad resuelta, constituyen un plus que no se reduce a lo autoconservativo y por otra parte se introducen de tal manera que cualquier estímulo que ingrese luego del lado de lo somático devendrá excitación. Quiere decir que se transforma lo que ingresa y esa cantidad excitante se va a ligar a lo que está representado, esto es la famosa alucinación primitiva. Lo que se alucina no es entonces el objeto del mundo, sino los residuos de una vivencia, no se alucina el pecho, se alucinan un conjunto de elementos, con lo cual lo extraordinario de eso que se ha producido es que tenemos una representación que proviniendo del exterior al mismo tiempo se convierte en realidad en sí, ha perdido toda referencia de su proveniencia exterior y el objeto que produce es un objeto no existente en el mundo. Aquí está presente el concepto de imaginación radical de Castoriadis, y la idea de que lo que se ha producido no tiene ningún tipo de existencia como objeto real aunque guarde los restos de esa 
experiencia del mundo, he ahí la segunda paradoja (Castoriadis, 1993). La representación que se constituye, siendo de proveniencia exógena pierde toda referencia y se convierte en algo del orden del psiquismo cuya materialidad ya no es la del mundo exterior. Son representaciones que se activan solas al estar investidas y tienen que encontrar un destino.

Finalmente, la tercera paradoja que va a señalar Bleichmar es que esas representaciones que se han producido en tiempos diversos van a encontrar retranscripciones hasta quedar reprimidas en el inconsciente de modo atemporal. Tales retranscripciones tienen la caracteristica de que siendo el efecto de un proceso histórico han perdido toda referencia al tiempo, no están atravesadas ni por el tiempo ni por espacios reales exteriores. Con lo cual son del orden de una ahistoricidad constitutiva que no deviene más que historicidad representada sólo para la conciencia o para el mundo exterior. En el inconsciente, tomando el modelo freudiano, el tiempo deviene espacio, no hay temporalidad, con lo cual los distintos elementos que se van produciendo históricamente quedan sedimentados en el psiquismo y sin embargo no son historizables en sí mismos porque no hay un sujeto capaz de organizar el tiempo ni la memoria. Entonces son el efecto de una historia que deviene representación ahistórica, ya que "en el inconsciente no está la historia de nadie, están las marcas de la historia" (Bleichmar, 1993: 48).

\section{Tercer Periodo: una intelectual de la esfera pública}

Decíamos en el inicio de este artículo que este último período incluía como novedad principal lo que denominábamos la vertiente de la participación de Bleichmar como intelectual de la esfera pública, y por lo tanto la publicación de todos los libros que podíamos colocar en la categoría de ensayo, tomando como punto de partida la crisis del 2001 en Argentina y el texto iniciático Dolor País. Por otra parte otra cuestión que se destaca con el inicio del nuevo siglo para la autora es el incremento de su participación en seminarios de posgrado en varias 
universidades nacionales y en países vecinos como Brasil y Uruguay. También empieza a dar clases en la Maestría de Psicología Educacional de la UBA, lo cual es significativo porque nos permite destacar otra problemática que iba a constituir tema de sus investigaciones: la constitución de la inteligencia en sus relaciones con la constitución del psiquismo (Bleichmar, 2009b).

Bleichmar definía la inteligencia como capacidad de operar sobre el mundo, es decir la posibilidad que tiene un sujeto de instrumentar un conjunto de variables en función de transformar algún tipo de realidad en la cual se encuentra inmerso, estableciendo de inicio que no tiene nada que ver con el inconsciente en sentido estricto. Conocimiento e inteligencia van a quedar separados del inconsciente en tanto ambos suponen una operatoria sobre esos pensamientos sin sujeto, átomos o embriones de la simbolización. Esto quiere decir que si bien la cría humana es antecedida por una estructura de lenguaje, por las estructuras de la cultura, eso no significa que los tiempos de constitución y los modos de la inteligencia vayan a ser canónicos, genéricos o universales. El planteo involucraba a la vez un trabajo sobre el concepto de génesis, que para la autora debía ser descapturado de un sentido que fue tomando a partir del ingreso del estructuralismo en nuestro país. Para Bleichmar la idea de génesis quedó homologada a la de desarrollo evolutivo y no a un sistema de recorridos de carácter histórico. Otra vez aparece aquí la crítica al estructuralismo como responsable del borramiento del eje de lo histórico. Para redondear una primera aproximación, el planteo de Bleichmar va a girar en torno a la idea de que la inteligencia también se construye, por lo tanto se puede producir, es decir que así como la intervención analítica podía producir neogénesis en términos de propiciar o destrabar un proceso de constitución de un aparato psíquico o de la instalación de la represión originaria que dé lugar a la presencia y existencia de un sujeto, del mismo modo esa organización propiciará la constitución de la inteligencia. Se produce un entramado donde ambas cuestiones son solidarias, y donde entonces el modelo teórico-clínico puede operar como un modelo de detección temprana en relación al tema de la 
inteligencia también. A nivel del diagnóstico, se tratará de establecer hasta qué punto está constituido el aparato, poniéndolo en correlación con la perturbación, el trastorno, o el motivo de consulta "pedagógico". El objetivo sería diferenciar -a partir de dicha correlación- entre lo que va a llamar trastorno de aprendizaje y lo que denominará trastorno de la constitución de la inteligencia. Si hay fallas en la constitución del aparato, va a haber necesariamente fallas en la constitución de la inteligencia, y la importancia de detectarlo es establecer las prioridades correspondientes, dado que muchas veces se indican diversas variantes de apoyo escolar o pedagógico sin identificar que puede haber un problema estructural de fondo. Los desarrollos sobre la constitución de la inteligencia hacia finales del segundo periodo anticiparon $\mathrm{y}$ prepararon el terreno para uno de los ejes principales de este último período: la subjetividad, sus modos de producción y las novedades del siglo XXI, el concepto de sujeto, la perspectiva de género y las nuevas formas de la sexualidad. Entonces, en la categoria que llamamos metapsicológica se manifiesta un interés por la refundación conceptual de temáticas íntimamente ligadas (y necesarias) al eje de su participación como intelectual reflexiva al servicio de la sociedad y de los ensayos que iba publicando en los medios. Basta como ejemplo mencionar los títulos de los libros editados en este período: por un lado La subjetividad en riesgo y El desmantelamiento de la subjetividad; por otro lado Paradojas de la sexualidad masculina, en el cual los diversos capítulos trataban otras variantes de los modos de la sexualidad actuales además de la masculina, tema desplegado luego en toda su amplitud en Las teorías sexuales en psicoanálisis (Bleichmar, 2005; 2006, 2009 y 2014). Por último, La construcción del sujeto ético y Vergüenza, culpa y pudor, reflejando su vocación de poner énfasis en la reconstrucción del tejido social y los lazos con el semejante (Bleichmar, 2011 у 2016).

En Paradojas de la sexualidad masculina, Bleichmar introdujo una novedad de enorme importancia clínica para una actualización metapsicológica de lo que llamaremos una teoría de las masculinidades. Demuestra cómo en muchos casos es posible cuestionar la lectura 
freudiana que al referirse a la función paterna pone el énfasis exclusivamente en el carácter interdictor. A partir de la experiencia clínica, la autora demuestra la existencia en algunos varones de fantasias homosexuales muchas veces necesarias para el acceso a la posición masculina (de allí el carácter paradojal que subraya). Hace trabajar el concepto freudiano de identificación primaria para mostrar cómo el niño también toma como objeto erótico de amor al padre, lo cual tendría sus origenes en aquellas primerísimas inscripciones vinculadas a los cuidados precoces en los cuales el padre cumple un papel importante al participar de los mismos como metonimia de la madre. Por lo tanto también se inscriben elementos vinculados al cuerpo y la erogeneización producida en el intercambio con el niño, que se reactivarán en un tiempo posterior. La identificación al padre implicaría entonces la incorporación del pene paterno (fantasía que Bleichmar encuentra en la clínica y que no puede fundamentarse desde la idea de una perversión como en su momento se hizo) cuestión que aporta elementos insoslayables de tener en cuenta en el interior de la práctica con niños en tiempos de constitución subjetiva, así como en la clínica con adultos que consultan por la enorme perturbación que el retorno de estas fantasías reprimidas pueden acarrearles.

En el mismo trabajo, Bleichmar orientaba transformaciones conceptuales en la teoría psicoanalítica en dirección a la inclusión de las diversidades sexuales al proponer que los denominados trastornos de la identidad de género no eran del orden de la perversión, así como no lo era la homosexualidad, ni las formas consensuadas múltiples con las cuales los seres humanos se encuentran en la resolución de los destinos del placer.

¿Cómo redefinir el problema de la perversión hoy? Considero que las variables presentes en la definición clásica, tanto con relación al complejo de castración como a la dominancia de las zonas erógenas llamadas pregenitales, es muy poco defendible (Bleichmar 2006: 85).

Por otra parte, en los textos dedicados al problema de la producción de subjetividad, señalaba que la misma remite a los modos históricos de 
constitución de los sujetos en el interior de cada sociedad y que debía ser diferenciada específicamente de lo inconsciente. Agregaba que el sujeto es una categoría filosófica, lógica y lingüística emparentada con la noción de subjetividad, que implica la posibilidad de ordenamiento espacio-temporal del mundo y dirigido a una intencionalidad exterior. Así considerada, la noción de sujeto se opone a la de inconsciente (que está regido por la legalidad del proceso primario y por la ausencia de temporalidad, negación, lógica del tercero excluido e intencionalidad) y debería ser reubicada del lado del yo. Así, los conceptos de subjetividad $\mathrm{y}$ sujeto no pueden remitir al funcionamiento del psiquismo en su conjunto ya que excluyen al inconsciente y su legalidad; en este sentido la autora afirma que lo inconsciente es propiamente para-subjetivo:

Lo dificil de asir es el carácter profundamente para-subjetivo del inconsciente, y el hecho de que la realidad psíquica, en sus orígenes mismos, es eso, realidad, al margen de toda subjetividad y conciencia, vale decir, realidad pre-subjetiva, lo cual constituye el rasgo fundamental de su materialidad. Que una vez constituido el sujeto, esta realidad pase a ser para-subjetiva, da cuenta de lo irreductible del modo de funcionamiento del inconsciente como ajeno a toda significación, a toda intencionalidad, res extensa, no cogitation. La resubjetivización del inconsciente,la intencionalización del inconsciente, el recentramiento de un sujeto en el inconsciente que actuaría más allá de mí pero que sería otro, es justamente la imposibilidad de entender esta cuestión tan radical planteada por Freud. Que el sujeto fuera lo que representa un significante para otro significante era una manera de marcar que se había terminado con el sujeto, pero mucha gente lo entendió como que estaba en otro lado. Entonces en el fondo estaba la verdad, el significante, marcando la posición del sujeto deseante...Y con ello la reintroducción de un sujeto trascendental pero un tantito degradado en el inconsciente (Bleichmar 2005: 83).

Finalmente, con sus seminarios sobre La construcción del sujeto ético y Vergüenza, culpa y pudor, la autora desplegaria lo que puede considerarse un verdadero aporte para un proyecto de reconstrucción de la subjetividad y la ética en la Argentina actual. Volvía a poner al discurso psicoanalítico a la altura de la función de incidir en la cultura en su sentido más amplio, poniendo el acento en la contraposición entre 
el sujeto ético y el sujeto disciplinado, y proponiendo volver a pensar la posibilidad de que nuestra sociedad produzca sujetos que, inscriptos en legalidades, sean capaces de construir una ética más allá de ellas (Bleichmar, 2011).

\section{Conclusiones}

La realidad histórico-social sobre la que se interviene en la actualidad desde una praxis psicoanalitica ha variado lo suficiente como para tornar necesaria y urgente la interrogación crítica del psicoanálisis sobre su propia red conceptual metapsicológica y los modos de la clinica que se desprenden del modo de concebirla. Esto permite interpelar la vigencia de algunos postulados por sobre otros que pueden quedar obsoletos al estar contaminados de una ideología solidaria de un tipo de producción de subjetividad característica de una época y de un sistema. El caso del modelo teórico-clínico diseñado por Bleichmar deviene relevante porque recupera la introducción de la historia acontecial, traumática y singular del sujeto en la constitución del psiquismo, y porque sostiene que la materialidad inscripta se organiza a partir de una descomposición y recomposición metabólica que liga de un modo diverso las representaciones, pensadas además en su heterogeneidad. Un modelo de aparato psíquico abierto a lo real implica que no sólo el presente no está exclusivamente determinado por el pasado, sino que también ese pasado puede ser recompuesto a partir de nuevas inscripciones y acontecimientos vinculados tanto al azar como a los efectos del trabajo realizado al interior de un dispositivo analítico.

Por otra parte, se trata de un modelo teórico-clínico que estudia y a la vez distingue tanto la producción de subjetividad como la constitución, organización y funcionamiento del psiquismo, lo cual permite luego la investigación de los puntos de contacto entre ambas dimensiones. Esta capacidad de cruzar dichas dimensiones puede renovar la potencia heurística del psicoanálisis salvaguardando su fecundidad y alcance explicativo a lo largo del tiempo, en la medida en que provee de las herramientas necesarias para revisar en cada época las pregnancias 
ideológicas que puedan parasitar la red conceptual al plegarse a premisas derivadas de la producción de subjetividad de cada tiempo histórico-social.

\section{Referencias Bibliográficas}

Bleichmar, S. (1986). En los origenes del sujeto psíquico. Buenos Aires: Amorrortu.

Bleichmar, S. (1990). Lecturas de Freud. Buenos Aires: Lugar.

Bleichmar, S. (1993). La fundación de lo inconsciente. Buenos Aires: Amorrortu.

Bleichmar, S. (1994). "Repetición y temporalidad: una historia bifronte". En: S. Bleichmar (comp.), Temporalidad, Determinación y Azar. Lo reversible y lo irreversible, pp.45-76. Buenos Aires: Paidós.

Bleichmar, S. (2000). Clínica psicoanalitica y neogénesis. Buenos Aires: Amorrortu.

Bleichmar, S. (2002). Dolor País. Buenos Aires: Libros del Zorzal.

Bleichmar, S. (2005). La subjetividad en riesgo. Buenos Aires: Topía.

Bleichmar, S. (2006a). No me hubiera gustado morir en los 90. Buenos Aires: Taurus.

Bleichmar, S. (2006b). Paradojas de la sexualidad masculina. Buenos Aires: Paidós.

Bleichmar, S. (2008). Violencia social, violencia escolar. De la puesta de límites a la construcción de legalidades. Buenos Aires: Noveduc.

Bleichmar, S. (2009a). Superar la inmediatez. Un modo de pensar nuestro tiempo. Buenos Aires: Ediciones del CCC.

Bleichmar, S. (2009b). Inteligencia y simbolización. Una perspectiva psicoanalítica. Buenos Aires: Paidós.

Bleichmar, S. (2009c). El desmantelamiento de la subjetividad y el estallido del yo. Buenos Aires: Topía.

Bleichmar, S. (2010). Psicoanálisis extramuros. Puesta a prueba frente a lo traumático. Buenos Aires: Entreideas. 
Bleichmar, S. (2011). La construcción del sujeto ético. Buenos Aires: Paidós.

Bleichmar, S. (2014). Las teorias sexuales en psicoanálisis. Buenos Aires: Paidós.

Bleichmar, S. (2016). Vergüenza, culpa y pudor. Buenos Aires: Paidós.

Calabresi, C. \& Polanco, F. (2011). La Psicología y su enseñanza en Argentina. Entrevista con Hugo Klappenbach. Universitas Psychologica, 10 (2), 613-626.

Carpintero, E. y Vainer, A. (2004). Las huellas de la memoria. Buenos Aires: Topia.

Castoriadis, C. (1993). Lógica, imaginación, reflexión. En: R. Dorey (ed.), El inconsciente y la ciencia. Buenos Aires: Amorrortu.

Dagfal, A. (2004). Para una 'estética de la recepción' de las ideas psicológicas. Frenia, Revista de Historia de la Psiquiatría, 5, 1-12.

Dagfal, A. (2009). Entre París y Buenos Aires. La invención del psicólogo. Buenos Aires: Paidós.

Ey, H. (1970). Coloquio de Bonneval. México: Siglo XXI.

Freud, S. (1915/1986). Lo inconsciente. En Obras Completas, Tomo XIV. Buenos Aires: Amorrortu.

Freud, S. (1925/1986). La negación. En Obras Completas, Tomo XIX. Buenos Aires: Amorrortu.

Green, A. (1990). De locuras privadas. Buenos Aires: Amorrortu.

Hornstein, L. (1995). Ni sin Lacan ni solo Lacan. Revista Zona Erógena (23), 11-13.

Jauss, H. (1978). Pour une esthetique du reception. Paris: Gallimard.

Jauss, H. (1981). Estética de la recepción y comunicación literaria. Punto de Vista, 12, 34-40.

Klappenbach, H. (2000). El psicoanálisis en los debates sobre el rol del psicólogo. Argentina, 1960-1975. Revista Universitaria de Psicoanálisis, 2, 191-227.

Laplanche, J. (1981). El estructuralismo ¿sí o no?. Trabajo del Psicoanálisis , 1 (1), 15-34.

Laplanche, J. (1981). Editorial. Trabajo del Psicoanálisis , 1 (1), 7-14. 
Laplanche, J. (1987). Nuevos fundamentos para el psicoanálisis. Buenos Aires: Amorrortu.

Laplanche, J. (1996). La prioridad del otro en psicoanálisis. Buenos Aires: Amorrortu.

Plotkin, M., \& Visacovsky, S. (2007). Saber y autoridad: intervenciones de psicoanalistas en torno a la crisis en la Argentina. Revista Estudios interdisciplinarios de América Latina y el Caribe, 18, 1340 .

Rifflet-Lemaire, A. (1971). Lacan. Barcelona: Edhasa.

Schenquerman, C. (2001). Paradigmas de la clínica psicoanalítica: espirales del tiempo transcurrido en la práctica psicoanalítica. Revista Aperturas Psicoanaliticas, 9.

Starcenbaum, M. (2014). Marxismo, estructuralismo y psicoanálisis: itinerarios de Althusser en la cultura psicoanalitica argentina (1965-1976). En: A. Popovitch, (ed), Althusser desde América Latina, pp. 121-148. Buenos Aires: Biblos.

Urribarri, F. (2009). Después de Lacan: del poslacanismo al psicoanálisis contemporáneo. Revista de Psicoanálisis (APA), 4(LXVI), 665-686.

Varela, M. (2002). “Recepción”. En C. Altamirano (ed.), Términos críticos de sociología de la cultura, pp. 195-198. Buenos Aires: Paidós.

Vezzetti, H. (1983). Situación actual del psicoanálisis. Punto de Vista, 19, 4-7.

Vezzetti, H. (1994). El psicoanálisis y la esfera pública. Punto de Vista, $50,19-22$.

Vezzetti, H. (1998). Las psicologías del fin de siglo a la luz de su historia. Revista de Psicología General y Aplicada 51(1), 105-114.

Viguera, A. (2005). Justificación del concepto de Signos de percepción para una Metapsicología de lo Originario. Actas de las XII Jornadas de investigación de la Facultad de Psicología, UBA, Primer encuentro de investigadores en Psicología del Mercosur.

Viguera, A. (2006). Signos de percepción y Atractores extraños. Actas de las XIII Jornadas de investigación de la Facultad de Psicología, 
UBA, Segundo encuentro de investigadores en Psicología del Mercosur.

Viguera, A. (2007). Signos de percepción y Memorias Indecibles. Actas de las XIV Jornadas de investigación de la Facultad de Psicología, UBA, Tercer encuentro de investigadores en Psicología del Mercosur.

Viguera, A. (2013). Las enseñanzas de Raúl Sciarretta en la universidad de las catacumbas. Revista de Psicología -segunda época-, 13, 209-229. 